\title{
Indole Compound
}

National Cancer Institute

\section{Source}

National Cancer Institute. Indole Compound. NCI Thesaurus. Code C54677.

Any compound that contains the basic indole structure, an aromatic heterocyclic org anic compound, consisting of a six-membered benzene ring fused to a five-membered nitrogen-containing pyrrole ring. 